Open Access

\title{
'A bite before bed': exposure to malaria vectors outside the times of net use in the highlands of western Kenya
}

Mary K Cooke1, Sam C Kahindi², Robin M Oriango², Chrispin Owaga ${ }^{2}$, Elizabeth Ayoma², Danspaid Mabuka², Dennis Nyangau², Lucy Abel ${ }^{2}$, Elizabeth Atieno ${ }^{2}$, Stephen Awuor ${ }^{2}$, Chris Drakeley ${ }^{1}$, Jonathan Cox ${ }^{1}$ and Jennifer Stevenson ${ }^{1,3^{*}}$

\begin{abstract}
Background: The human population in the highlands of Nyanza Province, western Kenya, is subject to sporadic epidemics of Plasmodium falciparum. Indoor residual spraying (IRS) and long-lasting insecticide treated nets (LLINs) are used widely in this area. These interventions are most effective when Anopheles rest and feed indoors and when biting occurs at times when individuals use LLINs. It is therefore important to test the current assumption of vector feeding preferences, and late night feeding times, in order to estimate the extent to which LLINs protect the inhabitants from vector bites.

Methods: Mosquito collections were made for six consecutive nights each month between June 2011 and May 2012. CDC light-traps were set next to occupied LLINs inside and outside randomly selected houses and emptied hourly. The net usage of residents, their hours of house entry and exit and times of sleeping were recorded and the individual hourly exposure to vectors indoors and outdoors was calculated. Using these data, the true protective efficacy of nets $\left(P^{*}\right)$, for this population was estimated, and compared between genders, age groups and from month to month.

Results: Primary vector species (Anopheles funestus s.l. and Anopheles arabiensis) were more likely to feed indoors but the secondary vector Anopheles coustani demonstrated exophagic behaviour $(p<0.05)$. A rise in vector biting activity was recorded at 19:30 outdoors and 18:30 indoors. Individuals using LLINs experienced a moderate reduction in their overall exposure to malaria vectors from 1.3 to 0.47 bites per night. The $P^{*}$ for the population over the study period was calculated as $51 \%$ and varied significantly with age and season $(p<0.01)$.

Conclusions: In the present study, LLINs offered the local population partial protection against malaria vector bites. It is likely that $P^{*}$ would be estimated to be greater if the overall suppression of the local vector population due to widespread community net use could be taken into account. However, the overlap of early biting habit of vectors and human activity in this region indicates that additional methods of vector control are required to limit transmission. Regular surveillance of both vector behaviour and domestic human-behaviour patterns would assist the planning of future control interventions in this region.
\end{abstract}

Keywords: Malaria, Exophagic, Endophagic, Anopheles funestus, Anopheles arabiensis, LLIN, IRS, Kenya, Highlands

\footnotetext{
*Correspondence: jennyc.stevenson@macharesearch.org

3 Johns Hopkins Malaria Research Institute, Johns Hopkins Bloomberg

School of Public Health/Macha Research Trust, Choma, Zambia

Full list of author information is available at the end of the article
} 


\section{Background}

The feeding locations and the biting times of individual Anopheles spp. could potentially confound assessments of their role in local malaria transmission $[1,2]$. There is evidence that in Kenya and elsewhere in Africa, primary vectors and other potentially important secondary malaria vectors do not feed exclusively within houses $[1,3-14]$ and that significant levels of vector exophagy, feeding outdoors, can occur at times when the human population is still outdoors [5, 7, 11-13, 15, 16]. Malaria eradication has recently returned to the global health agenda for the first time since the failure of the Global Malaria Eradication Programme (GMEP) of the 1950s and 1960s [17-20]. The development of insecticide resistance, and the exophily and exophagy of Anopheles species (resting and feeding outdoors) are thought to be among the key contributors to the failure of the original programme [21] which relied heavily on indoor residual spraying (IRS) with DDT. It has, therefore, been suggested that any future campaign to achieve eradication, still less elimination, may fail if the lessons learnt from the collapse of the GMEP are forgotten or ignored [20, 22].

Today, vector malaria elimination plans are heavily reliant on the use of long-lasting insecticide treated nets (LLINs) and IRS, both of these being strategies that are theoretically less effective against the malaria vectors that are fully or partially exophilic or exophagic [23]. Successful malaria control is threatened by the emergence of physiological, biochemical or behavioural adaptations within the vector population in response to the use of insecticide $[24,25]$. IRS and LLINs require direct contact between the mosquito and surfaces carrying sufficient levels of insecticide to kill or repel the vector. Pre-existing or adapted feeding and resting behaviour may reduce or negate this contact [19].

The feeding behaviour and circadian rhythms of Anopheles are genetically determined [26, 27], with the former being linked with inversion polymorphisms [26]. There is an added complication of intraspecies variation, where mosquitoes of the same species but different homokaryotypes react to identical environmental conditions in different ways [26]. There has been some debate surrounding the importance of pre-existing exophilic and exophagic Anopheles populations when planning control efforts $[1,19,28-30]$. Whilst the occurrence and mechanisms of insecticide resistance over the last century have been well documented in African Anopheles populations $[21,25,31]$, the extent to which the emergence of population-wide vector behavioural change in response to control methods, known as 'behaviouristic resistance', affects the use of nets and IRS remains unclear. This can only be established by observing vector population behaviour in the field and there is a lack of basic pre-intervention baseline studies [12, 25, 31-34].

The time of feeding in both endophagic and exophagic populations may also be of critical importance if it occurs in the hours outside of LLIN use [16, 28, 30, 35-38], particularly in areas where nets are the main control intervention used [1].There have been reports of net and IRS use leading to a reduction in indoor biting or resting, and a shift to exophagic behaviour, earlier feeding times or feeding on different hosts [10, 39-48]. In Kenya, a pronounced reduction in endophily was observed in the vectors Anopheles gambiae sensu stricto (s.s.) and Anopheles funestus sensu lato (s.l.) and a shift in host preference from humans to other mammals after 5 years of bed-net use [44]. Similarly, host choice change in An. funestus s.l. was observed by Githeko et al. following use of permethrin-impregnated eave-sisal curtains [49]. In Benin, $A n$. funestus s.l. populations exhibited increased exophagy and a shift in feeding times after LLIN introduction and demonstrated a shift to diurnal feeding in a recent study in Senegal [50, 51]. For these species complexes, this could be due to a change of the sibling species composition, rather than a behavioural change of a single species per se, as some members demonstrate higher zoophagy and exophagy than others. This was demonstrated in Kenya where following mass net distribution the $A n$. gambiae s.s. population decreased and the remaining sibling species Anopheles arabiensis, demonstrated higher exophagy and zoophagy [52]. In Tanzania, substantial reduction in the indoor resting and a small increase in the exophagic behaviour of An. gambiae s.s. was recorded after the introduction of pyrethroid-impregnated bed nets in one study village [39]. It should also be noted, that these changes are not universal, a recent study in Kenya noted that late night vector feeding behaviour still persisted in areas 10 years after bed net distribution [53].

Human behaviour may also influence the extent of human-vector contact. Entomological studies carried out in Zambia and Tanzania incorporated the proportion of the human population indoors but not asleep and those indoors and asleep under an LLIN, in order to calculate the protective efficacy of bed nets $[37,38,45]$. The methodology of these studies provides a useful insight into the true protective efficacy of bed nets when both human and vector behaviours are combined but are partially limited, as they do not estimate the area-wide effects on the vector population that universal coverage of LLIN can offer [54].

The World Health Organization recommends that adequate baseline information is collected in an area before residual insecticide is used [55]. Without a good understanding of the baseline entomological situation, the emergence of true behavioural adaptations will be 
difficult to detect. This concern has led to a call for regular monitoring of vector feeding behaviour as control programmes are expanded [37]. Regrettably, as noted by Smits et al., vector control is susceptible to a reduction in supervision and evaluation when activities have been in place for some time [4]. Success is more likely if control efforts are designed to adapt to changing local conditions [4]. Without a baseline vector dataset it is difficult to identify the emergence of behaviouristic resistance, and the accuracy of malaria transmission models used to plan future control efforts will be compromised [56-58].

This study aimed to assess the behaviour of exophagic or partially exophagic malaria vectors in Rachuonyo South, western Kenyan highlands, over different seasons, and to assess the level of exposure to Anopheles bites that individuals experience when not protected by an LLIN. Using vector exposure calculations, the protective efficacy of nets was calculated for this population.

\section{Methods}

\section{Study site}

The current Kenyan national malaria strategic plan aims to reduce morbidity and mortality caused by malaria, using current control tools, including regular national mass distributions of LLINs and IRS in selected regions [59]. The western Kenyan highlands are considered an area of unstable Plasmodium falciparum transmission and prone to epidemics, and as such are included in those areas selected for intensive malaria control by universal LLIN distribution and either annual or intermittent IRS [60-62]. Malaria transmission in this region is characterized by marked temporal and spatial heterogeneity $[49,63,64]$. The identification of malaria vectors, their behaviour and the contribution of each vector to local transmission are key to evaluating the success of control measures, and to planning future campaigns [2, 37, $56,57]$. This is particularly important in areas of unstable transmission which constitute key targets for eliminating the disease as vector dynamics can vary dramatically by season [65-67]. In Nyanza Province, western Kenya, a number of descriptive studies have been carried out in Kisii district of vector distribution and behaviours in the context of control interventions $[68,69]$. However in the highland fringe area of neighbouring Rachuonyo South, a district of approximately 200,000 population bordering the highly endemic lake area, no recent data exist on vector bionomics.

This study was carried out under the highland Malaria Transmission Consortium in southern Nyanza Province, Kenya in the adjacent villages of Lwanda and Siany, in Rachuonyo South District ( $0^{\circ} 25^{\prime} 59.53^{\prime \prime}$ S, 34 $55^{\prime} 40.36^{\prime \prime}$ E; altitude 1,420-1,570 m ASL). This location was previously identified as an area of relatively high $P$. falciparum transmission during cross-sectional and cohort parasitological surveys carried out in 2009 and 2010 and with indoor-resting anopheline populations [70]. IRS had been carried out by the local health services in this region in 2010 using Fendona (alphacypermethrin), a year before the study began, and was repeated in July 2011 using Icon (Lambda-cyhalothrin). This area was also included in the mass distribution of LLINs during the rainy season (April-June) in 2011, as part of the Kenyan National Malaria Strategy [71]. However, prior to the distribution in 2011, $100 \%$ of the 48 houses recruited into the present study already owned a minimum of one net (and more than half of the households owned two or more nets).

In western Kenya the primary vectors of $P$. falciparum are considered to be, An. arabiensis, An. funestus and An. gambiae s.s., three of the six malaria vector species identified in Kenya [72, 73]. There is some evidence that the once widely distributed An. gambiae s.s. has declined in recent years and that $A n$. arabiensis has encroached upon its previous distribution [52, 73, 74]. This shift has been attributed to the wide-scale use of insecticide-treated nets (ITNs) [44, 52].

\section{Sample size}

The study was designed to compare the catch of lighttraps set outdoors with those placed indoors over 1,800 trap nights, 900 trap nights for each study arm over a 1-year period. To test the null hypothesis that there was no difference between the mean density of primary malaria vector species feeding inside and outside houses, data from a previous field study in the region were used to estimate minimum sample sizes. As there was the potential for intracluster correlation caused by repeated sampling at trap locations, formulae for community studies from Hayes and Bennett were used [75]. The minimum sample size required to compare An. gambiae s.l. feeding inside and outside, with $80 \%$ power, $95 \%$ precision and a coefficient of variation of 0.8 was 7.9 traps in each study arm per night, giving a total of 16 traps in use per study night. Using the same power, precision and coefficient estimates, a total of 8.4 traps per study arm would be required to compare the mean catches of $A n$. funestus s.l. As previous studies had been disrupted by unexpected weather conditions (outdoor catches, in particular, can be interrupted by heavy rain), a conservative total of 24 traps, 12 indoors and 12 outdoors, running each night was selected for the study.

\section{Mosquito collection}

Fieldwork was carried out between February 2011 and May 2012. Community sensitization, recruitment, mapping and a pilot study took place between February and May 2011. Sampling began in June 2011 and continued 
for six nights every lunar month (with the exception of December 2011) until the end of May 2012, a total of 75 collection nights. Sampling was scheduled on nights near a new moon to minimize the effect of moonlight on the outdoor light-trap collection and to reduce bias when comparing species distribution and flight activity across seasons [76-78]. An estimate of the presence and period of moonlight was calculated using a lunar calendar and the method described by Bowden [77, 79].

A stratified random sampling method was adopted to minimize sampling bias when selecting sampling locations and to reduce variance in the dataset [80]. The study site was identified with the aid of satellite imagery (Quickbird Inc, Longmont, CO, USA), with a spatial resolution of $<1 \mathrm{~m}$, which could therefore be used to identify structures on the ground. Using GIS software (ArcGIS 9.2, Redmond CA, USA), a sampling grid was defined to divide the area into 36 quadrants $(300 \mathrm{~m} \times 300 \mathrm{~m})$ covering an area of $1.8 \mathrm{sq} \mathrm{km}$ running across the valley floor and a portion of the adjoining hillsides.

A survey of the selected quadrants was conducted on the ground. Quadrants with permanent breeding sites $(n=13)$ were selected for recruitment, as these have been associated with higher adult vector productivity in highland areas than temporary breeding sites, and are more likely to be present throughout the sampling year [81] (Figure 1). Quadrants with fewer than four occupied houses were omitted from the recruitment. Remaining eligible quadrants were randomized and processed sequentially until 12 quadrants had been recruited into the study. Within each quadrant the mapped houses were randomized and four households with associated light-trap workers were recruited into the study. During recruitment, data on house construction, occupant numbers, bed nets, local IRS activity, and domestic animal ownership were collected.

To reduce selection bias six quadrants (i.e., 24 houses) were randomly selected for trapping each night. Within quadrants, two houses were randomly selected for outdoor sampling with the remaining two allocated for indoor trapping. As the effective range of light-traps has been estimated at $5 \mathrm{~m}$ [82], outdoor sampling took place at least $10 \mathrm{~m}$ from the house to reduce the chance of the inhabitants acting as unshielded bait. A miniature CDC light-trap with a standard $6.3 \mathrm{~V}$ incandescent bulb (Model 512, John W Hock, Florida, USA), with an LLIN occupied by a light-trap worker, was used to trap mosquitoes. Traps set indoors were hung in the sleeping quarters and traps set outside were hung adjacent to an occupied temporary, open-sided rain shelter constructed from a domed one-man tent (Kenya Canvas, Nairobi, Kenya).

Traps were checked and connected by 17:30 and the light-trap worker replaced the collection cups every hour until 22:30. The traps inside the houses continued to run until 05:30 the next morning when the collection cup was changed for the final hour. For traps set outside, no collections were made between 22:30 and 05:29 as it was assumed that all residents would be indoors between these times. These times were based on a survey of sleeping times carried out by Battle, recording sleeping times in rural Nyanza province, and are consistent with previous assumptions on sleeping times in rural areas and the scope of Anopheles activity [1, 83]. Between 05:29 and 06:30, a final hour of trapping was carried out both inside and outside. Supervisors made random checks throughout the night, every night, to ensure traps were running and set up correctly.

Mosquitoes were killed by freezing, and morphologically identified to genus and species level using morphological keys [84, 85]. A subsample of female Anopheles that were neither blood fed, gravid nor semigravid were dissected for determination of parity status as a proxy for age [86]. Samples were stored in $0.5-\mathrm{ml}$ micro centrifuge tubes packed with silica gel crystals and transported to the Centre for Global Health Research, Kenya Medical Research Institute/Centers for Disease Control and Prevention in Kisian, Kisumu (CGHR, KEMRI/CDC), for further analysis. Sibling species of the An. gambiae complex were identified using an An. gambiae specific diagnostic PCR [87]. The presence of P. falciparum or Plasmodium vivax CSP in specimens was tested by ELISA using an established methodology used by CGHR, KEMRI/CDC, adapted from techniques described by Beier et al. and Wirtz et al. [88, 89].

\section{Population sleeping and behaviour survey}

Questionnaires were used to gather information on the time people entered and exited their houses in the evening and morning, the time they slept and their use of bed nets. The head of each household used a digital watch to complete the questionnaire on behalf of all adults and children that slept in that house. Questionnaires were distributed and completed twice during each six-night sampling period, on a week night and a Saturday night, and collected the next day. Questionnaires were not distributed during the sampling week in December 2011 due to the short study period.

\section{Statistical analysis}

The location and times of Anopheles feeding behaviour were analysed using a random-effects negative binomial model accounting for repeated measurements using Stata (Version 11, StataCorp LP, Texas, USA). Bivariate analysis was carried out to assess the role of potential confounders, not on the causal pathway, against the outcome of interest. Those variables deemed not significant 


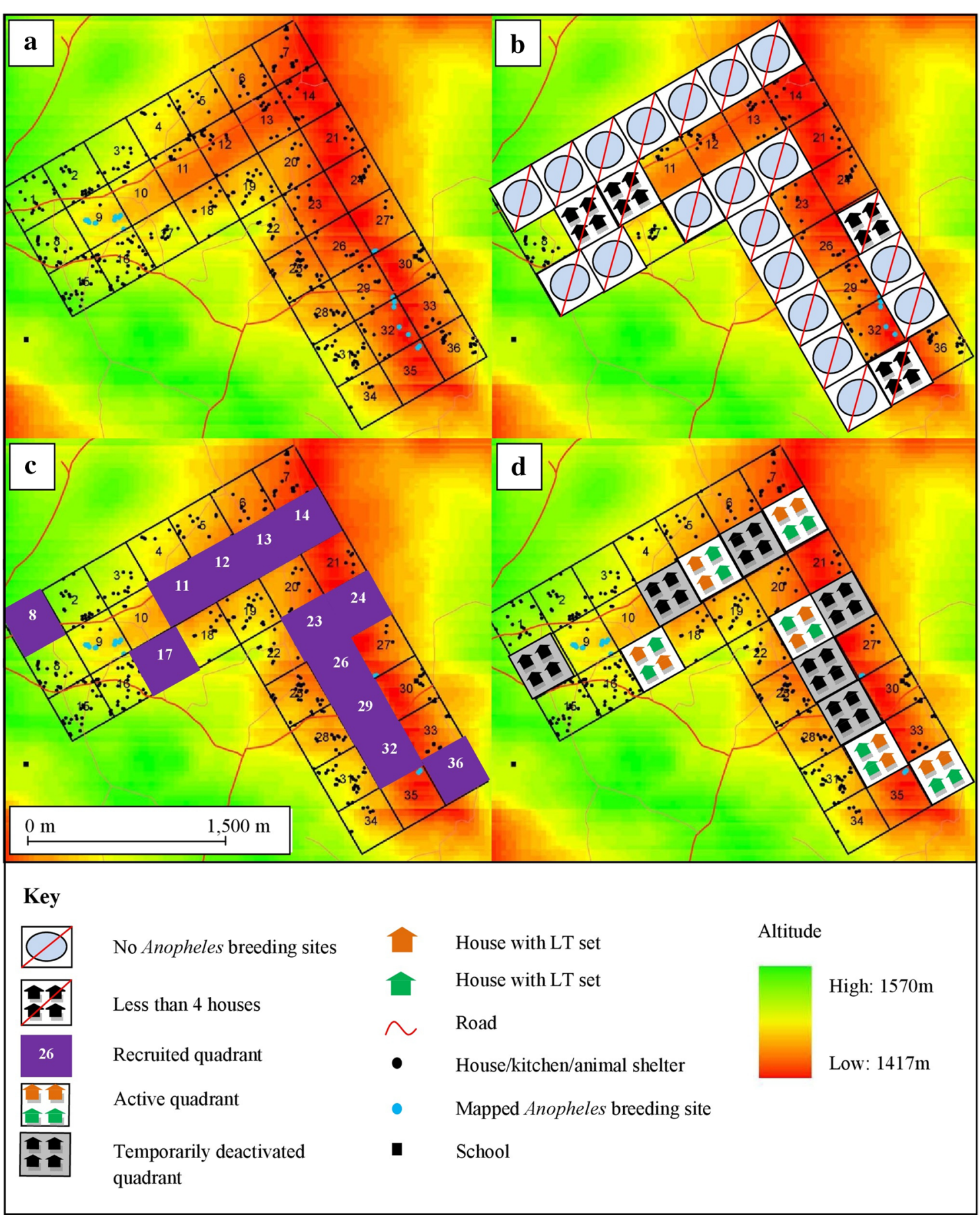

Figure 1 Maps of the study site showing the sampling quadrants, and phases of recruitment. a Construction of sampling grid and identification of building structures using aerial maps; $\mathbf{b}$ Survey of sampling grid to identify and exclude quadrants without breeding sites or with fewer than four houses; c Randomization of houses within the remaining quadrants and sequential recruitment of four houses per quadrant; $\mathbf{d}$ An example of a typical night of sampling, with six quadrants active and six quadrants deactivated.

( $p>0.05)$ were discarded. Independent variables were then tested for correlation using a Pearson's productmoment correlation test. Those demonstrating multicollinearity (correlation $>0.90$ ) were identified and one variable, from the two tested, chosen for the model. In all analyses, a predetermined significance level of $\mathrm{p}<0.05$ for the incident rate ratio (IRR) was sufficient evidence that the null hypothesis could be rejected. A model was 
deemed a poor fit if the Wald Chi squared test statistic $\left(\chi^{2}\right)$ had a $p>0.05$.

To determine whether there were groups within the local human population that were at greater risk of exposure to malaria vectors than others, the mean catch of $A n$. funestus s.l., An. arabiensis and An. gambiae s.s. trapped by hour and location were extracted for each sampling week and the man biting rate (MBR) for each hour that the traps were running was calculated for both locations. The potential exposure of individuals to these vectors was then estimated using each individual's responses to the sleeping questionnaire for the sampling week that the questionnaire was completed, thus creating a dataset that reflected any change to the vector-human interaction throughout the sampling year.

Human exposure to malaria vectors and the true protective efficacy of bed nets was calculated using methods adapted from the work described by Geissbuhler et al., based on the formulae published by Killeen et al. [37, 45] (see Additional file 1). These earlier studies calculated the protective efficacy of bed nets as a result of reduced exposure to An. gambiae bites, incorporating the proportion of the population indoors but not asleep and those indoors and asleep under an ITN. In the present study, calculations were made for exposure to the three primary vectors An. funestus s.l., An. arabiensis and An. gambiae s.s.

In this region it is rare for individuals to sleep outdoors at night, and this was excluded from the analysis. A limitation of this method is the necessary assumption that the protective efficacy of the bed nets $(\mathrm{P})$ is uniform between houses, and that each individual used an identical model and age of bed net, and used it correctly. There was a mass distribution of LLINs during this study, but there was evidence of older LLINs in use within the recruited households. In this calculation the functional protective efficacy of LLINs is assumed to be $80 \%(P=0.8)$, which had been adopted by previous studies informed by existing evidence from experimental hut trails $[37,45]$. We have also reported estimates that assume functional protective efficacy to be $100 \%$ for comparison purposes with other studies. Pairwise Kruskal-Wallis (K-W) analysis was used to compare $\mathrm{P}^{*}$ between participant age groups and month of data collection.

\section{Ethics}

Informed consent was obtained from those participating in the study. This work was reviewed and approved by the KEMRI/National Ethics Review Committee, Kenya (SSC No. 2007) and by the Ethics Committee of the London School of Hygiene and Tropical Medicine, UK. Informed consent was obtained from the head of each household recruited into the study and from every light-trap worker.

\section{Results}

Anopheles species identification and feeding behaviour

A total of 3,330 Anopheles were trapped between June 2011 and May 2012. Based on morphological identifications, the greatest proportion of female Anopheles were the vector species $A n$. funestus s.l. ( $\mathrm{n}=1,475,44 \%)$ and An. gambiae s.l. ( $\mathrm{n}=263$ 8\%). Anopheles funestus s.l. was the species most frequently trapped both inside and outside houses (inside: $\mathrm{n}=1,099,69 \%$ of females caught, and outside: $\mathrm{n}=376,33 \%)$. A total of 2,750 (99\%) of all Anopheles trapped were examined using An. gambiaespecific diagnostic PCR to identify sibling species. The remaining $1 \%$ of samples examined did not contain sufficient material to analyse. Using PCR, 145 were identified as $A n$. arabiensis (inside: $\mathrm{n}=110$, and outside: $\mathrm{n}=35$ ) and five samples were confirmed as An. gambiae s.s. (inside: $\mathrm{n}=5$, and outside: $\mathrm{n}=0$ ). The remainder did not amplify when tested, the majority of which had been morphologically identified as An. funestus s.l. Due to logistical constraints, PCR was not carried out to identify members of the An. funestus complex. This is a recognized limitation of this study which should be addressed by ongoing studies to genetically sequence these specimens.

When comparing indoor and outdoor catches directly at times when traps were running concurrently, there was evidence that $A n$. funestus s.l. were more likely to feed indoors than outdoors (IRR $=1.5$, 95\% CI: 1.1 2.010, $\mathrm{p}=0.006$ ) (Table 1 ). This species complex was also more likely to be trapped indoors when carrying eggs, when either semigravid or gravid (IRR $=4.5$, 95\% CI 2.5-8.2, p < 0.005). Combined, a total of $18.9 \%$ ( $\mathrm{n}=174$ ) An. funestus s.l. were identified as either semigravid or gravid. For collections carried out between the hours of 17:30 and 22:29 and 05:30 and 06:30 when people are likely to be outside of a net, An. funestus s.l. biting increased indoors between 18:30 and 19:29 $(\bar{x}=0.18$, 95\% CI $0.14-0.22)$ and $19: 30$ and $20: 29(\bar{x}=0.13,95 \%$ CI 0.10-0.15) with a third rise between 21:30 and 22:29 $(\bar{x}=0.16,95 \%$ CI $0.12-0.20$ ) (Figure 2). However, there was no evidence to indicate that the numbers recorded for these hours differed significantly $(p>0.1$ ). When compared directly to the numbers caught between 21:30 and 22:29, fewer An. funestus s.l. were likely to be trapped indoors very early in the evening (17:30-18:29: $\mathrm{p}<0.001)$, between $20: 30$ and $21: 39(\mathrm{p}=0.020)$ and in the early morning, 05:30-06:29 ( $\mathrm{p}<0.001)$. Outdoors $A n$. funestus s.l. females fed later between 19:30 and 20:29 $(x=0.21,95 \%$ CI $0.13-0.22)$ carrying through to $21: 30-$ 22:29 ( $x=0.076,95 \%$ CI 0.06-0.096, $\mathrm{p}<0.001)$.

Anopheles arabiensis was also caught in both indoor $(\mathrm{n}=67)$ and outdoor traps $(\mathrm{n}=35)$ and, was also more likely to feed indoors (IRR $=1.9,95 \%$ CI 1.03-3.4, 
Table 1 Female Anopheles morphologically identified vector species between the hours of 17:30 and 22:29 and 05:30 and 06:30

\begin{tabular}{|c|c|c|c|c|c|}
\hline \multirow[t]{2}{*}{$\begin{array}{l}\text { Outcome } \\
\text { measure }\end{array}$} & \multicolumn{2}{|c|}{$\begin{array}{l}\text { Total number } \\
\text { Anopheles } \\
\text { caught by trap } \\
\text { location }\end{array}$} & \multicolumn{3}{|c|}{$\begin{array}{l}\text { Comparison between indoors } \\
\text { and outdoors with outdoor } \\
\text { IRR }=1\end{array}$} \\
\hline & Indoor & Outdoor & $\begin{array}{l}\text { Indoor IRR } \\
(95 \% \mathrm{Cl})\end{array}$ & $\mathbf{P}$ & Wald $\chi^{2}(p)$ \\
\hline \multicolumn{6}{|c|}{ Primary African malaria vector species } \\
\hline $\begin{array}{l}\text { An. funestus } \\
\text { s.l. }\end{array}$ & 544 & 376 & $\begin{array}{r}1.5(1.1- \\
2.010)\end{array}$ & 0.006 & $18(<0.001)$ \\
\hline $\begin{array}{l}\text { An. arabi- } \\
\text { ensis }\end{array}$ & 67 & 35 & $1.9(1.03-3.4)$ & 0.038 & $17(0.0023)$ \\
\hline $\begin{array}{l}\text { An. gambiae } \\
\text { s.s. }\end{array}$ & 4 & 0 & NC & NC & NC \\
\hline An. nili & 1 & 1 & NC & NC & NC \\
\hline \multicolumn{6}{|c|}{ Other documented Kenyan Anopheles species } \\
\hline An. coustani & 19 & 151 & $\begin{array}{l}0.15(0.090- \\
0.25)\end{array}$ & $<0.001$ & $64(<0.001)$ \\
\hline $\begin{array}{l}\text { An. demeil- } \\
\text { Ioni }\end{array}$ & 63 & 148 & $\begin{array}{l}0.42(0.26- \\
0.68)\end{array}$ & $<0.001$ & $37(<0.001)$ \\
\hline An. dthali & 2 & 4 & $\begin{array}{l}0.52(0.080- \\
3.3)\end{array}$ & 0.49 & $2.3(0.32)$ \\
\hline An. gibbinsi & 1 & 11 & $\begin{array}{l}0.13(0.015- \\
1.08)\end{array}$ & 0.059 & $3.6(0.059)$ \\
\hline $\begin{array}{l}\text { An. longipal- } \\
\text { pis }\end{array}$ & 2 & 5 & NC & NC & NC \\
\hline $\begin{array}{l}\text { An. maculi- } \\
\text { palpis }\end{array}$ & 17 & 55 & $\begin{array}{l}0.31(0.16- \\
0.58)\end{array}$ & $<0.001$ & $25(<0.001)$ \\
\hline $\begin{array}{l}\text { An. natal- } \\
\text { ensis }\end{array}$ & 1 & 3 & $\mathrm{NC}$ & NC & $N C$ \\
\hline An. parensis & 1 & 2 & NC & NC & $\mathrm{NC}$ \\
\hline $\begin{array}{l}\text { An.preto- } \\
\text { riensis }\end{array}$ & 9 & 29 & $\begin{array}{l}0.41(0.18- \\
0.94)\end{array}$ & 0.035 & $9.02(0.011)$ \\
\hline An.rufipes & 5 & 26 & $\begin{array}{l}0.204(0.078- \\
0.54)\end{array}$ & 0.001 & $13(0.0012)$ \\
\hline An. salbaii & 2 & 7 & NC & NC & NC \\
\hline $\begin{array}{l}\text { An. squamo- } \\
\text { sus }\end{array}$ & 3 & 21 & $\begin{array}{l}0.22(0.056- \\
0.86)\end{array}$ & 0.029 & $9.6(0.0081)$ \\
\hline An. symesi & 4 & 4 & $\begin{array}{l}1.03 \\
(0.22-4.7)\end{array}$ & 0.97 & $0.00(0.97)$ \\
\hline An. ziemanni & 1 & 1 & NC & NC & NC \\
\hline
\end{tabular}

$N C$ negative binomial statistical model could not converge.

$\mathrm{p}=0.038)($ Table 1). A total of $12.7 \%(\mathrm{n}=13)$ An. arabiensis were identified as either semi-gravid or gravid. Indoor An. arabiensis biting activity started in the early evening between 18:30 and 19:29 $(\bar{x}=0.012,95 \% \mathrm{CI}$ $0.0042-0.020)$ and $19: 30$ and $20: 29(\bar{x}=0.011,95 \%$ CI $0.0033-0.018$ ) with a second rise in MBR between 21:30 and 22:29 ( $\bar{x}=0.026$, 95\% CI 0.015-0.040) (Figure 2). However, there was no evidence to indicate that the two periods of increased activity differed in intensity $(p>0.1)$. Outdoor biting started later in the evening with activity

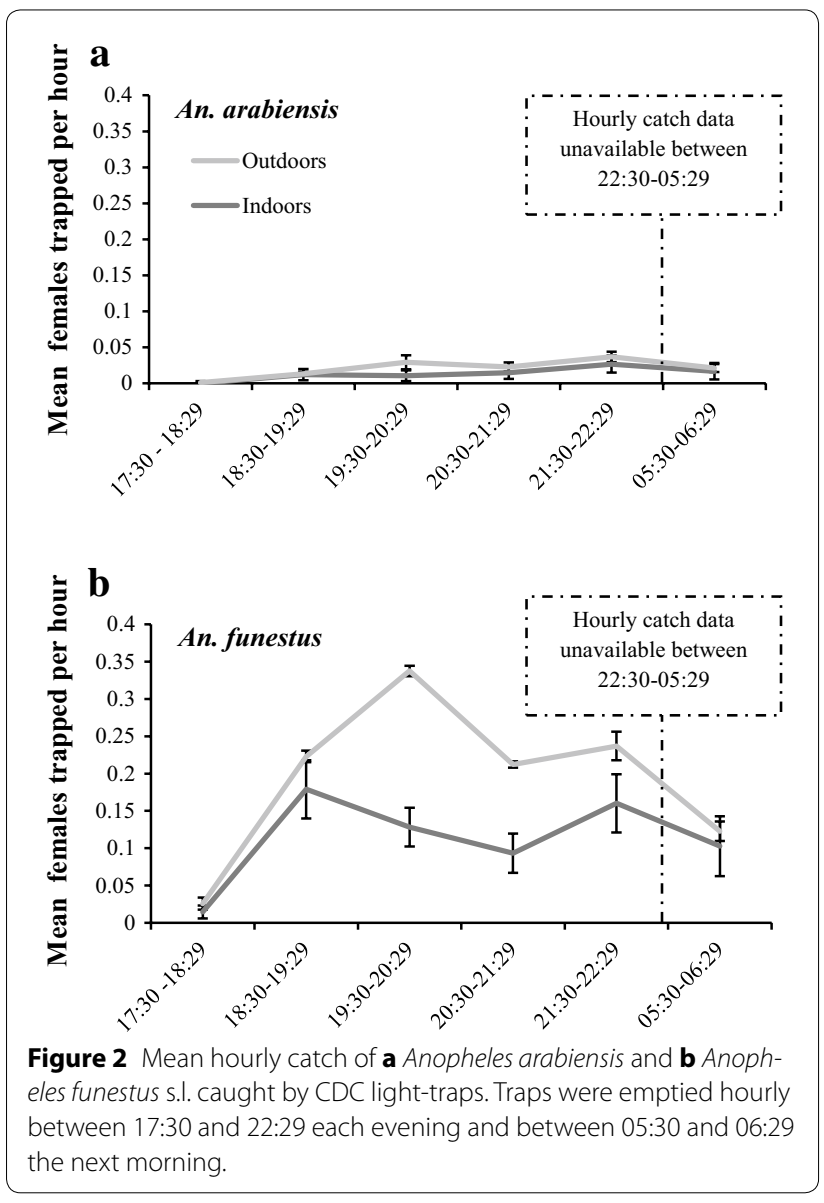

increasing between 19:30 and 20:29 ( $\bar{x}=0.019,95 \% \mathrm{CI}$ $0.01-0028)$ and continuing until 22:29 ( $<<0.001)$. There was significantly less activity in the early hours of the evening (18:30-19:29: $\mathrm{p}<0.05)$ when compared to the numbers recorded between 21:30 and 22:29.

A total of four An. gambiae s.s. females were trapped between the hours of 17:30 and 22:29 and 05:30 and $06: 29$, all indoors. The increase in the indoor mean hourly MBR occurred between 20:30 and 21:29 $(\bar{x}=0.0027$, $95 \% \mathrm{CI}-0.0010$ to 0.0064$)$. There were insufficient data to make a comparison between the hour of biting or the numbers of An. gambiae s.s. found inside and outside.

A smaller number of samples were morphologically identified as those that have been previously documented in Kenya and may represent infrequent or secondary malaria vectors $[14,73,90]$. Of these, An. coustani, Anopheles demeilloni, An. maculipalpis, Anopheles pretoriensis, Anopheles squamosus, and Anopheles rufipes females were predominantly trapped outdoors $(\mathrm{p}<0.05)$. Samples of other species were too few in number to fit the model (Table 1).

There was evidence that older Anopheles females that had previously laid eggs (parous mosquitoes) 
were more likely to bite outdoors $(\mathrm{p}<0.05)$ and, conversely, that younger nulliparous females were more likely to feed indoors $(\mathrm{p}<0.05)$. However, when analysing the catch of malaria vector species: An. funestus s.l. (55\% parous indoor, $78 \%$ outdoor), An. arabiensis (78\% indoor, $80 \%$ outdoor) and An. gambiae s.s. (100\% indoor, $0 \%$ outdoor) there was either insufficient data to fit a model, or the model did not fit well (Wald $\chi^{2}$ $\mathrm{p}>0.05$ ). There was a similar difficulty when fitting models to the other Anopheles species that had been dissected (Wald $\chi^{2} \mathrm{p}>0.05$ ), with the exception of An. coustani. A total of 44 An. coustani were successfully dissected, with $77 \%(\mathrm{n}=34)$ identified as parous (indoor $\mathrm{n}=4,12 \%$ and outdoor $\mathrm{n}=30,88 \%$ ). There was some evidence that parous An. coustani females were more likely to forage outdoors (IRR $=0.26,95 \%$ CI 0.091-0.77, $\mathrm{p}=0.05$ ).

\section{Entomological inoculation rate (EIR)}

A subset ( $\mathrm{n}=2,706,98 \%)$ of female Anopheles were tested for the presence of $P$. falciparum and P. vivax CSP, these samples included those from indoor traps left running between 22:30 and 05:30. Five samples were not tested due to sample damage. Of the samples tested, P. falciparum CSP was detected in 44 samples $(1.6 \%)$ (Table 2). The majority of infected Anopheles were morphologically identified as An. funestus s.l. ( $\mathrm{n}=30,69 \%$, $2.0 \%$ CSP positive). Other morphologically identified species included An. demeilloni (2.7\% CSP positive) An. gibbinsi (7.7\% CSP positive) and An. longipalpis (12.5\% CSP positive). One sample of An. arabiensis (contained $P$. falciparum CSP (0.7\%). Plasmodium vivax CSP was not detected from any of the samples tested.

The estimated annual EIR was calculated using the indoor collections, as indoor data spanned the complete sampling night from 17:30 to 05:30 the next morning. The EIR for this region, was 20 (95\% CI 17-22) P. falciparuminfected bites per person per year. Estimates of the mean indoor EIR per person per night were calculated for the study period and these ranged between no infected bites per person per night and a maximum of 0.27 (95\% CI 0.22-0.32) recorded in March 2012.

\section{Protective efficacy of bed nets}

The true mean bed net protective efficacy $\left(\mathrm{P}^{*}\right)$, calculated as efficacy against the combined bites of primary malaria vectors (see Additional file 1) was estimated at 51\% (95\% CI 50-53\%) if nets were assumed to offer protection against $80 \%$ of vector bites and $64 \%$ (95\% CI 62-66\%) if they were $100 \%$ effective. This equates to a drop in efficacy of $29 \%$ (95\% CI $27-30 \%$ ) if bed nets are assumed to offer protection against $80 \%$ of vector bites when used correctly. The $\mathrm{P}^{*}$ calculated for each sampling month ranged from 45 to $56 \%$ (Figure 3). Protective efficacy varied significantly across the sampling year when taking into consideration the protection offered against the bites of all primary malaria vectors $\left(\mathrm{K}-\mathrm{W} \chi^{2}=37,11 \mathrm{df}, \mathrm{p}=0.0001\right)$, An. funestus s.l. alone (K-W $\chi^{2}=37,11 \mathrm{df}, \mathrm{p}=0.0001$ ), An. arabiensis $\left(\mathrm{K}-\mathrm{W} \chi^{2}=230,11 \mathrm{df}, \mathrm{p}=0.0001\right)$ and $A n$. gambiae s.s. (K-W $\left.\chi^{2}=170,11 \mathrm{df}, \mathrm{p}=0.0001\right)$.

The estimated proportion of indoor and outdoor exposure to malaria vectors fluctuated significantly across the sampling year $\left(\mathrm{K}-\mathrm{W} \chi^{2}=147,11 \mathrm{df}, \mathrm{p}=0.0001\right)$ (Figure 3), with a peak in the proportion of outdoor exposure to the primary vectors in early October 2011 (with bed net: $27 \%, 95 \%$ CI $19-34 \%$ and without bed net: 9.7\%, 95\% CI 7-12\%). When tested using the two-sample Mann-Whitney test, there was no significant difference in the outdoor exposure to malaria vectors between men and women $(\mathrm{M}-\mathrm{W}, \mathrm{z}=0.35, \mathrm{p}=0.72)$, or between

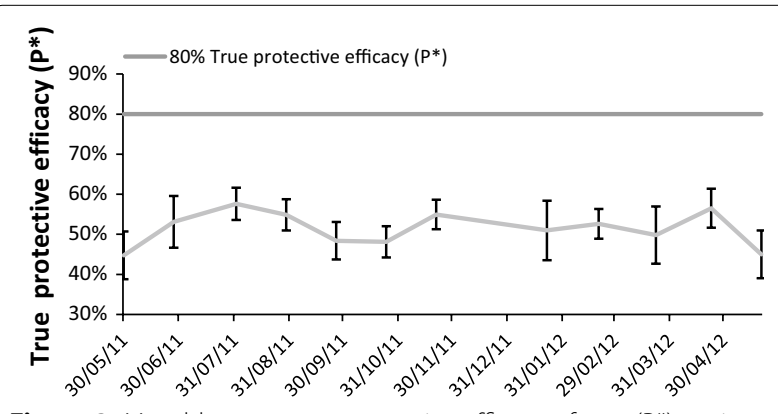

Figure 3 Monthly mean true protective efficacy of nets ( $\left(P^{*}\right)$ against the combined bites of primary malaria vectors. For the purpose of this study, primary malaria vectors are defined as An. nili, An. funestus s.l. and An. gambiae s.l.

Table 2 Percentage of $P$. falciparum CSP positive, blood fed and parous primary vector species trapped between the hours of 17:30 and 22:29 and 05:30 and 06:30

\begin{tabular}{lllllll}
\hline Primary vector species & \multicolumn{3}{l}{ \% CSP positive } & \multicolumn{2}{c}{ \% blood fed } & \% parous \\
\hline An. funestus s.l. & $2.0 \%$ & $(\mathrm{n}=30)$ & $14.1 \%$ & $(\mathrm{n}=130)$ & $66 \%$ & $(\mathrm{n}=126)$ \\
An. arabiensis & $0.7 \%$ & $(\mathrm{n}=1)$ & $13.7 \%$ & $(\mathrm{n}=14)$ & $79 \%$ & $(\mathrm{n}=11)$ \\
An. gambiae s.s. & $0.0 \%$ & $(\mathrm{n}=0)$ & $0.0 \%$ & $(\mathrm{n}=0)$ & $100 \%$ & $(\mathrm{n}=1)$ \\
An. nili & $0.0 \%$ & $(\mathrm{n}=0)$ & $50 \%$ & $(\mathrm{n}=1)$ & $0.0 \%$ & $(\mathrm{n}=0)$ \\
\hline
\end{tabular}


participants' exposure on a week night as opposed to a night at the weekend $(\mathrm{M}-\mathrm{W}, \mathrm{z}=1.1, \mathrm{p}=0.26)$.

The $\mathrm{P}^{*}$ of LLINs also varied with the age group of participants $\left(\mathrm{K}-\mathrm{W} \chi^{2}=147,18 \mathrm{df}, \mathrm{p}=0.0001\right)$, for $A n$. funestus s.l. alone (K-W $\left.\chi^{2}=144,18 \mathrm{df}, \mathrm{p}=0.0001\right)$, An. arabiensis $\left(\mathrm{K}-\mathrm{W} \chi^{2}=119,17 \mathrm{df}, \mathrm{p}=0.0001\right)$ but it was not significant for the small number of An. gambiae s.s. trapped $\left(\mathrm{K}-\mathrm{W} \chi^{2}=14,13 \mathrm{df}, \mathrm{p}>0.1\right)$. When individual age groups were compared against the reference age group of under 9 years, those aged 10-59 had significantly different levels of $\mathrm{P}^{*}$ than those aged under 9 years $(p<0.001)$, and examination of the medians and means indicate that the levels of $\mathrm{P} *$ are lower in these age groups (Figure 4).

\section{Indoor versus outdoor exposure}

Based on the times recorded during the survey, it was estimated that individuals not using bed nets would experience a mean of $95 \%$ of their total vector exposure inside their houses (95\% CI 95-96\%), and 5\% outdoors (95\% CI 4-5\%). It was estimated that a mean 31\% (95\% CI $29-33 \%$ ) of their daily exposure occurred indoors before they went to bed. A mean of $64 \%$ (62-66\%) of daily exposure occurred while they were asleep. When individuals used bed nets their estimated mean exposure reduced from 1.3 vector bites per night (95\% CI $1.2-1.3 \%$ ) to 0.47 (95\% CI 0.44-0.51) (Figure 5).

\section{Discussion}

In common with the previous work carried out in Zambia and Tanzania to determine the protective bed net efficacy, this study highlights the importance of integrating human behaviour into the assessment of human-vector contact in relation to malaria transmission $[16,37,38$, 45]. Despite predominantly endophagic primary vectors in this region, the overall $\mathrm{P}^{*}$ was low at 51\% (95\% CI 50-53\%) and this may be explained by exposure occurring indoors at times of the evening before nets are used which equates to $31 \%$ of total mean daily exposure. This is substantially lower than the bed net efficacy using similar methods reported from rural Tanzania [37], but higher than that reported from urban Tanzania where An. arabiensis is predominantly exophagic [45]. In the present study, $90-95 \%$ of vector exposure was calculated to occur within the house if LLINs were not used, which is similar to levels reported for An. funestus s.l. in Zambia [38] and the results of a study of matched surveys of human and mosquito behaviour from Burkina Faso, Tanzania, Zambia, and Kenya [91]. The use of LLINs in the present study reduced an individual's exposure from 1.3 bites per night to 0.47 bites per night. In agreement with a recent study carried out in Western Kenya the majority of exposure occurred indoors [53], an estimated 65\% of mean daily exposure occurred during sleeping hours, indicating that nets still may offer personal protection in an area of low transmission.

The two primary vector species An. funestus s.l. and $A n$. arabiensis were both active inside and outside from 18:30 onwards, two-and-a-half hours before the mean time local residents reported going to bed. When studying mosquito activity outside times when individuals are likely to be asleep, the peak hours of biting varied between species, but universally very little activity occurred during the early evening (17:30-18:29) and

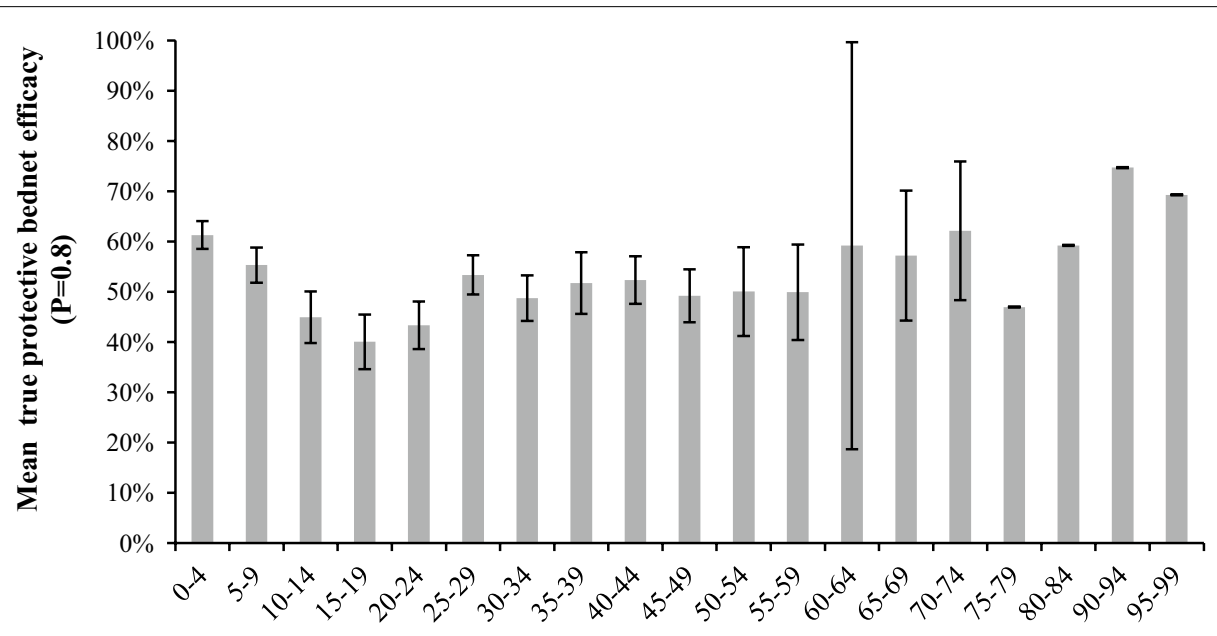

Age group (years)

Figure 4 Variation in mean true protective efficacy of nets $\left(P^{*}\right)$ by age group of participants. Calculations based on a bed net efficacy where nets are estimated to prevent $80 \%$ of bites when used correctly. 


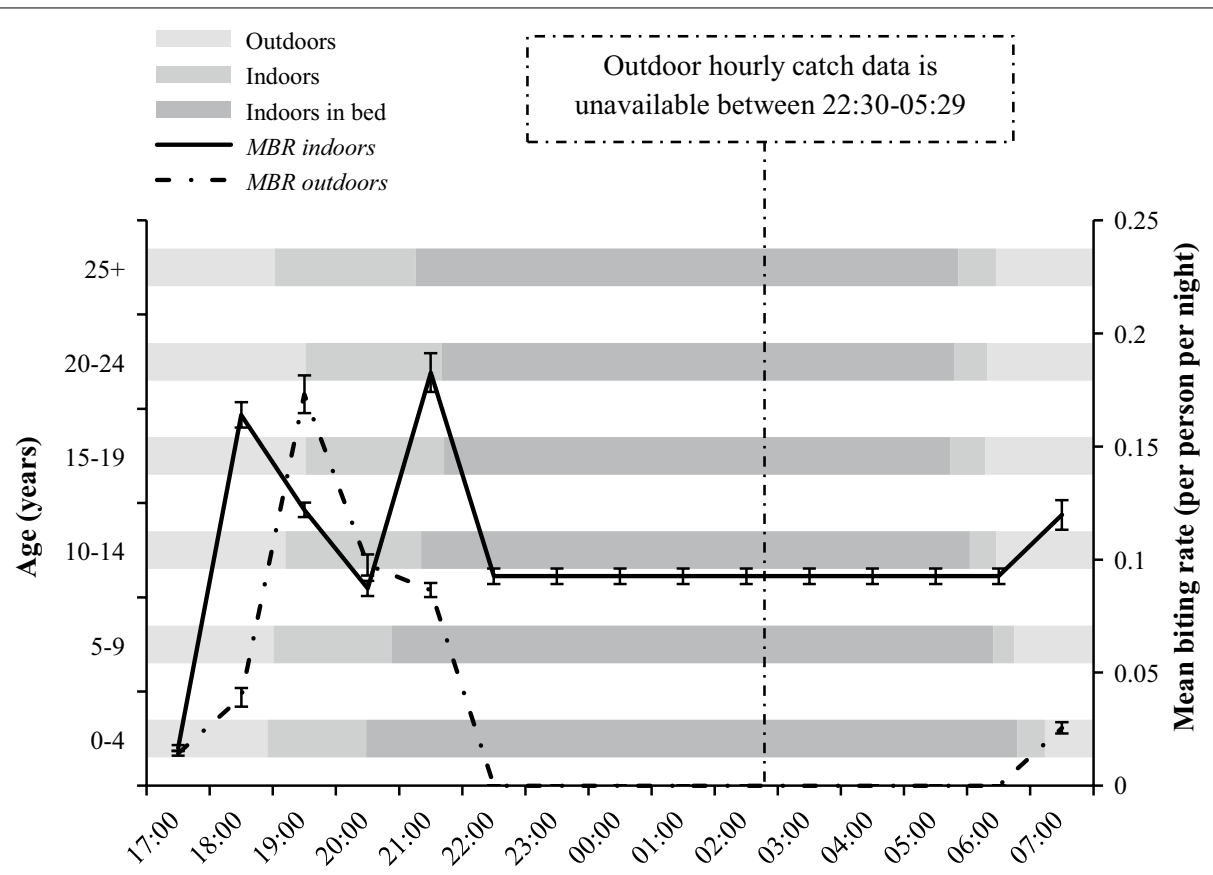

Figure 5 Combined hourly man biting rate (MBR) for Anopheles arabiensis and Anopheles funestus s.l. Biting activity overlaid on the reported movements of the local human population indoors and outdoors before, during and after sleep (mean hours). Data for outdoor hourly MBRs were not collected between the hours of 22:30-05:29. For diagrammatic proposes, data for indoor MBR estimates between the hours of 22:30-05:29 were divided equally across the $7 \mathrm{~h}$ of collection. Data collected between June 2011 and May 2012.

morning (05:30-06:29). The latter may be due to the low dawn temperatures in this area, but the former may have been influenced by the heat and light intensity in the hours before dusk. During the times studied, An. funestus s.l. demonstrated a distinct bimodal pattern of indoor feeding activity, with the first increase in biting activity between 18:30 and 20:30 followed by a second at 21:30 and 22:29. Although there was no evidence that these periods differed in intensity $(\mathrm{p}<0.05)$, they were both significantly higher than the preceding or interim hours $(\mathrm{p}<0.05)$.

The residents of this area reported that $90 \%$ used nets, greater than that previously recorded in Kakamega in the western Kenyan highlands (56\%) [92], or by the Malaria Indicator Survey in 2010, 61\% [62]. However, the former survey was conducted in a different area with a different ethnic populations. Furthermore, the area of the current study was a research site where active health teams had been working for the past 2 years and data were collected during a year of mass LLIN distribution with prolonged marketing campaigns to increase awareness and adherence. Net use recorded in the present study may not reflect wider patterns of bed net use.

It is important to note that this study, in common with previous work $[16,37,38,45]$, did not estimate the area-wide effects on the vector population that may result from universal coverage of LLIN [54]. It has been shown that mass distribution will reduce transmission of principally endophagic vectors by reducing the reservoir of disease [16]. The P* estimated here may be an underestimation as it does not include any potential communitywide effects.

Anopheles funestus s.l. was the most abundant primary vector species trapped in the area throughout the year with an indoor MBR of 0.15-1.2 and an outdoor MBR of 0.13-1.2 bites per person per night. Similar findings were reported from lowland areas in Nyanza Province [93]. Anopheles funestus s.s. is considered the anthropophagic exception in a complex of zoophagic species [94], so it is likely that the An. funestus s.l. in this study contain other morphologically identical members of the complex. Work continues to genetically sequence the full set of anophelines caught to confirm species identities. Alternatively, it is possible that the LLIN and IRS use in this area has induced this species to seek alternative hosts. Such phenotypic, plastic feeding behaviour has been observed in An. gambiae s.s., which can demonstrate zoophilic behaviour in field conditions if their preferred human hosts are not readily available [95]. This shift from anthropophagy to zoophagy was noted in Kenyan 
An. funestus s.l. populations in response to permethrinimpregnated eaves-sisal curtains [42] but again no data were given as to the sibling species of the complex.

Anopheles arabiensis was also present in the study site, with a peak MBR of 0.12 bites per person per night. This is not consistent with either the historical distribution of this species or recent work carried out in the Nandi hills, where An. gambiae s.s. females were more prolific than An. arabiensis $[72,96]$. However, these findings do align with the observations of Ndenga et al. who surveyed larval breeding sites above $1,500 \mathrm{~m}$ in neighbouring Western province, where An. arabiensis represented a third of the An. gambiae s.l. larvae collected [74]. Anopheles arabiensis is found at high densities in lowland Nyanza and it is therefore conceivable that this species has encroached upon the neighbouring highland fringe areas, filling the niche left by $A n$. gambiae s.s., which was selectively targeted by local control efforts [41, 44, 52,68]. It is possible that the distribution of An. arabiensis may have always included highland areas, with this species being overlooked by those studies that predominantly used indoor traps that do not target outdoor-resting and feeding species [74].

EIR estimates were higher than those previously reported for similar areas of western Kenya [49, 63]. Ndenga et al. reported an EIR of 0.2-1.1 in highland areas of the neighbouring district Kisii Central and in Kakamega (neighbouring province) and Githeko et al. recorded a peak EIR of 12.8 from comparable elevations in Kakamega [49, 63]. Those studies may have underestimated the EIR as they used pyrethrum spray catches, which will not trap endophagic and exophilic Anopheles that are infected but exit the house early. Furthermore, in the current study, the site was specifically selected due to high $P$. falciparum prevalence and incidence and high indoor-resting densities of anopheline mosquitoes. Within this area of higher transmission, only houses within quadrants that contained breeding sites were selected, and thus the EIR from the present study could be interpreted as that of a transmission 'hotspot' [97]. In common with studies that used methods other than human landing catches (HLC) to estimate EIR [98], the present study did not include an estimation of outdoor transmission and thus potentially overestimated the total exposure an individual will experience throughout the year. In addition to these limitations, it is also possible that the EIR may be overestimated. This study did not include steps to limit false-positive CSP-ELISA results by reanalysing the homogenate therefore it is possible that false-positives were included in the EIR estimate [99].

Across all Anopheles species trapped, there was evidence $(\mathrm{p}<0.05)$ that females carrying eggs were 4.5 times more likely to feed indoors, potentially presenting a higher transmission risk indoors as these mosquitoes are older than nulliparous females. However, unfed parous females without eggs are used as a proxy for older females and were more likely to bite outdoors $(\mathrm{p}<0.05)$ and, conversely, younger nulliparous females were more likely to feed indoors $(\mathrm{p}<0.05)$. Therefore, the number of gravid females caught in traps indoors may reflect the recruitment of the female indoor-resting population that are attracted to the CDC-light trap during egg development.

The findings of this study support the hypothesis that the levels of both LLIN and IRS coverage are currently not sufficient to interrupt transmission in this setting. IRS should be an effective control tool in a region where the majority of exposure occurs inside the house and should complement the use of LLINs if biting occurs before times of net use and/or the observed exophagy is also accompanied by indoor-resting behaviour. IRS was and is still implemented in Rachuonyo district but coverage at the time was not universal, with $38 \%$ of houses sprayed in the previous 12 months [62]. Improving the coverage of the current IRS campaign may be more effective, but if conducted poorly it may also encourage the development of insecticide resistance. Therefore, as the majority of exposure is currently occurring indoors, measures to bar entry to Anopheles may be a cost-effective option to complement existing interventions. These could include the use of ceilings, window and door screens, measures that have successfully reduced the number of Anopheles indoors both historically and in experimental hut trials $[100,101]$.

An important limitation of the present study is the use of light-traps outdoors. Light-traps have been in use since the early part of the 20th century, and have been used widely in a variety of transmission settings, including Africa [56, 82, 102]. These traps work on the principle that the mosquito is drawn into the 'dazzle zone', at which point the fan mechanism sucks them into the trap [78, 102]. The exact mechanics of this process and the extent to which it is species-specific are not well understood $[102,103]$. The type and size of catch may be influenced by a number of factors, including the species of mosquito [78], the model of trap and the wavelength of the light used [102] and whether the strength of illumination can be kept constant. Indeed, it is reasonable to assume that the traps used during the present study could not achieve a uniform level of illumination throughout the night.

Light-traps have several practical advantages: they are commercially available which aids standardisation [104], they are easily accepted by communities within study sites [105] and they have low running costs. A number of experiments have been carried out to establish whether light-trap catches correlate well with those from HLC and some studies have indicated that light-trap catches 
of Anopheles have relatively high sporozoite rates [103105]. Other studies have reported no significant difference between sporozoite rates from light-traps and HLC, with a corresponding similarity in parity rates between these trapping methods [106-108]. With a lack of standardisation between studies, there appears to be no definitive evidence to indicate whether light-traps, with or without human bait, can catch the anthropophagic vector population.

It has been claimed that CDC light-traps cannot be used outdoors [109], yet this appears to be based on limited evidence. The small number of studies that assessed HLC with light-traps hung outside tended to place the light-traps directly under the eaves of houses [110, 111], either with an accompanying light-trap inside the same house $[110,112]$ or with no accompanying human bait [110, 113]. Costantini et al. (1998) did hang CDC lighttraps away from houses, under a thatched rain shelter with human bait, but found no correlation between its catch and that of HLC when comparing An. gambiae s.l. However, when $A n$. funestus numbers were compared there was a density-dependent correlation between the catch of the outdoor HLC and the CDC light-trap [114]. The authors concluded that outdoor traps were not effective but acknowledged that this was based on a limited data set [114]. Overgaard et al. (2012) used a CDC light-trap with a UV bulb outdoors but with no human bait and reported a correlation between the numbers of An. gambiae s.l. and An. melas trapped by the two lighttraps. The authors did, however, express some doubts about the practicality of using light-traps outdoors with such low numbers and such high levels of variability between catches [110]. Currently, there is insufficient evidence to definitively dismiss the use of light-traps outdoors as a means of collecting anthropophagic Anopheles. Where HLC is not available, light-traps remain one of the few viable trapping methodologies not designed solely to catch the resting Anopheles population, and may represent a useful tool to catch the vector population.

The present study contributes to the knowledge of both primary and secondary vector species dynamics in the fringe area of the western Kenyan highlands. The existence of predominantly exophagic potential secondary vector species such as $A n$. coustani and An. demeilloni should be an important consideration when planning future control efforts, as they are likely to be overlooked during campaigns targeted at the primary vector species that feed indoors during sleeping hours. These species have the potential to maintain low levels of transmission in this area. It is therefore vital that entomological surveillance should be carried out on a regular basis in this area and in other regions of unstable malaria transmission targeted for malaria control or future malaria elimination.

\section{Conclusions}

The present study indicates that primary vectors are more likely to feed indoors in the fringe of the western Kenyan highlands. Exophagic behaviour does occur, but when considered in conjunction with the human behaviour recorded in this study, the majority of exposure occurs indoors. However, surveillance must be maintained to detect any shift in behaviour and to monitor exophagic populations of potential secondary vectors. Greater exposure to primary vector bites occurs indoors in the early evening when LLINs are not used. The early biting habit of these vectors was shown to reduce the protective efficacy of LLINs, although the actual estimate of protective efficacy calculated here does not take into account the mass effect on mosquito populations when an entire community uses nets. There are indications that exposure and therefore protective efficacy of nets varies with both an individual's age and across seasons. A key aspect of man-vector contact is the behaviour of the human local population, and this is not static across the seasons. These results indicate that LLINs may theoretically reduce malaria vector exposure if used correctly, but that other measures are required to protect against early indoor biting. Regular surveillance of both vector behaviour and domestic human-behaviour patterns are needed for the planning of future control interventions in this region.

\section{Additional file}

Additional file 1: Calculation of true bed net protective efficacy. The document details the method used to calculate true bednet protective efficacy.

\section{Abbreviations}

CSP: circumsporozoite protein; ELISA: enzyme-linked immunosorbent assay; EIR: entomologial inoculation rate; GMEP: Global Malaria Eradication Programme; HLC: human landing catches; IRR: incident rate ratio; IRS: indoor residual spraying; ITN: insecticide-treated nets; KEMRI/CDC: Kenya Medical Research Institute/Centers for Disease Control and Prevention in Kisian, Kisumu; LLIN: long lasting insecticidal net; MBR: man biting-rate; $\mathrm{P}^{*}$ : true protective efficacy; PCR: polymerase chain reaction.

\section{Authors' contributions}

MC, JS, JC and CD conceived and designed the study. MC, SK, RO, CO, EA, DM, $D N, L A, E A$, and JS performed the experiment, contributed to study design and entered and cleaned the data. MC performed the data analysis. MC, JS and JC wrote the paper. All authors read and approved the final manuscript.

\section{Author details}

${ }^{1}$ Faculty of Infectious and Tropical Diseases, London School of Hygiene and Tropical Medicine, London, UK. ${ }^{2}$ Kenya Medical Research Institute Centre for Global Health Research/Centers for Disease Control and Prevention, Kisumu, Kenya. ${ }^{3}$ Johns Hopkins Malaria Research Institute, Johns Hopkins Bloomberg School of Public Health/Macha Research Trust, Choma, Zambia. 


\section{Acknowledgements}

We are grateful to the staff of the Highland MTC team for their hard work and we would particularly like to thank, Silas Otieno, Diana Okello-Mburu and Wycliffe Odongo. We would also like to thank the staff at the Centre for Global Health Research, Kenya Medical Research Institute/Centres for Disease Control and Prevention, (CGHR, KEMRI/CDC) Kisumu and the Ifakara Health Institute (Tanzania) for their support of this project. We thank Brandy St Laurent and Neil Lobo at the Eck Institute for Global Health, University of Notre Dame, Indiana, USA for arranging and carrying out the sequencing of samples. We are grateful to the residents of Lwanda and Siany (Rachuonyo South) for their hospitality, tolerance and their contribution to this work. We would particularly like to thank our guides George Onyango and Hezron Adika for their invaluable help. This work was funded by the MTC by the Bill \& Melinda Gates Foundation (USA) Grant Number 45114 and a DTA studentship Grant from the Medical Research Council (UK). This article has been approved by the Director of the Kenya Medical Research Institute.

\section{Compliance with ethical guidelines}

\section{Competing interests}

The authors declare that they have no competing interests.

Received: 23 December 2014 Accepted: 6 June 2015

Published online: 25 June 2015

\section{References}

1. Pates H, Curtis C (2005) Mosquito behavior and vector control. Annu Rev Entomol 50:53-70

2. Molineaux L, Shidrawi GR, Clarke JL, Boulzaguet JR, Ashkar TS (1979) Assessment of insecticidal impact on the malaria mosquito's vectorial capacity, from data on the man-biting rate and age-composition. Bull World Health Organ 57:265-274

3. Fornadel CM, Norris LC, Franco V, Norris DE (2011) Unexpected anthropophily in the potential secondary malaria vectors Anopheles coustani s.l. and Anopheles squamosus in Macha, Zambia. Vector Borne Zoonotic Dis 11:1173-1179

4. Smits A, Coosemans M, van Bortel W, Barutwanayo M, Delacollette C (1995) Readjustment of the malaria vector control strategy in the Rusizi Valley, Burundi. Bull Entomol Res 85:541-548

5. Aniedu I (1993) Biting activity and resting habits of malaria vectors in Baringo district, Kenya. Anz Schädlingskd Pfl Umwelt 66:72-76

6. Ravoahangimalala R, Randrianambinintsoa E, Tchuinkam T, Robert $V$ (2008) Paludisme en milieu urbain d'altitude Antananarivo, Madagascar bioécologie d'Anopheles arabiensis. Bull Soc Pathol Exot 101:348-352

7. Shililu J, Ghebremeskel T, Seulu F, Mengistu S, Fekadu H, Zerom M et al (2004) Seasonal abundance, vector behavior, and malaria parasite transmission in Eritrea. JAMA 20:155-164

8. Oyewole IO, Awolola TS, Ibidapo CA, Oduola AO, Okwa OO, Obansa JA (2007) Behaviour and population dynamics of the major anopheline vectors in a malaria endemic area in southern Nigeria. J Vector Borne Dis 44:56-64

9. Muturi EJ, Kamau L, Jacob BG, Muriu S, Mbogo CM, Shililu J et al (2009) Spatial distribution, blood feeding pattern, and role of Anopheles funestus complex in malaria transmission in central Kenya. Parasitol Res 105:1041-1046

10. Moiroux N, Gomez MB, Pennetier C, Elanga E, Djènontin A, Chandre F et al (2012) Changes in Anopheles funestus biting behaviour following universal coverage of long-lasting insecticidal nets in Benin. J Infect Dis 206:1622-1629

11. Fornadel CM, Norris LC, Glass GE, Norris DE (2010) Analysis of Anopheles arabiensis blood feeding behavior in southern Zambia during the two years after introduction of insecticide-treated bed nets. Am J Trop Med Hyg 83:848-853

12. Reddy MR, Overgaard HJ, Abaga S, Reddy VP, Caccone A, Kiszewski AE et al (2011) Outdoor host seeking behaviour of Anopheles gambiae mosquitoes following initiation of malaria vector control on Bioko Island, Equatorial Guinea. Malar J 10:184. doi:10.1186/1475-2875-10-184
13. Tirados I, Costantini C, Gibson G, Torr SJ (2006) Blood-feeding behaviour of the malarial mosquito Anopheles arabiensis: implications for vector control. Med Vet Entomol 20:425-437

14. Mwangangi JM, Mbogo CM, Orindi BO, Muturi EJ, Midega JT, Nzovu J et al (2013) Shifts in malaria vector species composition and transmission dynamics along the Kenyan coast over the past 20 years. Malar J $12: 13$

15. Mendis C, Jacobsen JL, Gamage-Mendis A, Bule E, Dgedge M, Thompson R et al (2000) Anopheles arabiensis and An. funestus are equally important vectors of malaria in Matola coastal suburb of Maputo, southern Mozambique. Med Vet Entomol 14:171-180

16. Govella NJ, Okumu FO, Killeen GF (2010) Insecticide-treated nets can reduce malaria transmission by mosquitoes which feed outdoors. Am J Trop Med Hyg 82:415-419

17. Tanner M, de Savigny D (2008) Malaria eradication back on the table. Bull World Health Organ 86:81-160

18. Roberts L, Enserink R (2007) Did they really say... eradication? Science 318:1544-1545

19. Ferguson HM, Dornhaus A, Beeche A, Borgemeister C, Gottlieb M, Mulla MS et al (2010) Ecology: a prerequisite for malaria elimination and eradication. PLoS Med 7:e1000303

20. Greenwood B (2008) Can malaria be eliminated? Trans R Soc Trop Med Hyg 103(Suppl 1):S2-S5

21. Bruce-Chwatt LJ (1984) Lessons learned from applied field research activities in Africa during the malaria eradication era. Bull World Health Organ 62(Suppl):19-29

22. Hommel M (2008) Towards a research agenda for global malaria elimination. Malar J 7(Suppl 1):S1

23. Bill and Melinda Gates Foundation (2011) Malaria: strategy overview. Seattle, USA

24. Muirhead-Thomson RC (1960) The significance of irritability, behaviouristic avoidance and allied phenomena in malaria eradication. Bull World Health Organ 22:721-734

25. Roberts DR, Andre A, Andre RG (1994) Insecticide resistance issues in vector-borne disease control. Am J Trop Med Hyg 50(Suppl 6):21-34

26. Coluzzi M (1992) Malaria vector analysis and control. Parasitol Today 8:113-118

27. Rund SSC, Hou TY, Ward SM, Collins FH, Duffield GE (2011) Genomewide profiling of diel and circadian gene expression in the malaria vector Anopheles gambiae. Proc Natl Acad Sci USA 108:E421-E430

28. Gillies MT (1956) The problem of exophily in Anopheles gambiae. Bull World Health Organ 15:437-449

29. Ribeiro H, Janz JG (1990) Exophagy and exophily in malaria vectors. Bull Soc Vector Ecol 15:185-188

30. Govella NJ, Ferguson H (2012) Why use of interventions targeting outdoor biting mosquitoes will be necessary to achieve malaria elimination. Front Physiol 3:199

31. Pant CP, Rishikesh N, Bang YH, Smith A (1981) Progress in malaria vector control. Bull World Health Organ 59:325-333

32. Baleta A (2009) Insecticide resistance threatens malaria control in Africa. Lancet 374:1581-1582

33. Busvine JR (1962) The problem of insecticide resistance. J Hyg Epidemiol Microbiol Immunol 6:243-255

34. Hess AC (1952) The significance of insecticide resistance in vector control programs. Am J Trop Med Hyg 1:371-388

35. Moiroux N, Damien GB, Egrot M, Djenontin A, Chandre F, Corbel V et al (2014) Human exposure to early morning Anopheles funestus biting behavior and personal protection provided by long-lasting insecticidal nets. PLoS One 9:e104967

36. Yohannes M, Boelee E (2012) Early biting rhythm in the Afro-tropical vector of malaria, Anopheles arabiensis, and challenges for its control in Ethiopia. Med Vet Entomol 26:103-105

37. Killeen GF, Kihonda J, Lyimo E, Oketch FR, Kotas ME, Mathenge E et al (2006) Quantifying behavioural interactions between humans and mosquitoes: evaluating the protective efficacy of insecticidal nets against malaria transmission in rural Tanzania. BMC Infect Dis $6: 161$

38. Seyoum A, Sikaala $\mathrm{CH}$, Chanda J, Chinula D, Ntamatungiro AJ, Hawela M et al (2012) Human exposure to anopheline mosquitoes occurs primarily indoors, even for users of insecticide-treated nets in Luangwa Valley, South-east Zambia. Parasit Vectors 5:101 
39. Gatton ML, Chitnis N, Churcher T, Donnelly MJ, Ghani AC, Godfray $\mathrm{HCJ}$ et al (2013) The importance of mosquito behavioural adaptations to malaria control in Africa. Evolution 67:1218-1230. doi:10.1111/ evo.12063

40. Padonou GG, Gbedjissi G, Yadouleton A, Azondekon R, Razack O, Oussou $O$ et al (2012) Decreased proportions of indoor feeding and endophily in Anopheles gambiae s.l. populations following the indoor residual spraying and insecticide-treated net interventions in Benin (West Africa). Parasit Vectors 5:262

41. Russell TL, Govella NJ, Azizi S, Drakeley CJ, Kachur SP, Killeen GF (2011) Increased proportions of outdoor feeding among residual malaria vector populations following increased use of insecticide-treated nets in rural Tanzania. Malar J 10:80. doi:10.1186/1475-2875-10-80

42. Githeko AK, Adungo NI, Karanja DM, Hawley WA, Vulule JM, Seroney IK et al (1996) Some observations on the biting behavior of Anopheles gambiae s.s., Anopheles arabiensis, and Anopheles funestus and their implications for malaria control. Exp Parasitol 82:306-315

43. Magesa SM, Wilkes TJ, Mnzava AE, Njunwa KJ, Myamba J, Kivuyo MD et al (1991) Trial of pyrethroid impregnated bednets in an area of Tanzania holoendemic for malaria. Part 2. Effects on the malaria vector population. Acta Trop 49:97-108

44. Mutuku FM, King CH, Mungai P, Mbogo C, Mwangangi J, Muchiri EM et al (2011) Impact of insecticide-treated bed nets on malaria transmission indices on the south coast of Kenya. Malar J 10:356

45. Geissbühler Y, Chaki P, Emidi B, Govella NJ, Shirima R, Mayagaya $V$ et al (2007) Interdependence of domestic malaria prevention measures and mosquito-human interactions in urban Dar es Salaam, Tanzania. Malar J 6:126

46. Charlwood JD, Graves PM (1987) The effect of permethrin-impregnated bednets on a population of Anopheles farauti in coastal Papua New Guinea. Med Vet Entomol 1:319-327

47. Braimah N, Drakeley C, Kweka E, Mosha F, Helinski M, Pates H et al (2005) Tests of bednet traps (Mbita traps) for monitoring mosquito populations and time of biting in Tanzania and possible impact of prolonged insect. Int J Trop Insect Sci 25:208-213

48. Takken W (2002) Do insecticide-treated bednets have an effect on malaria vectors? Trop Med Int Health 7:1022-1030

49. Githeko AK, Ayisi JM, Odada PK, Atieli FK, Ndenga BA, Githure Jl et al (2006) Topography and malaria transmission heterogeneity in western Kenya highlands: prospects for focal vector control. Malar J 5:107

50. Mourou JR, Coffinet T, Jarjaval F, Cotteaux C, Pradines E, Godefroy L et al (2012) Malaria transmission in Libreville: results of a one year survey. Malar J 11:40

51. Sougoufara S, Diédhiou SM, Doucouré S, Diagne N, Sembène PM, Harry $\mathrm{M}$ et al (2014) Biting by Anopheles funestus in broad daylight after use of long-lasting insecticidal nets: a new challenge to malaria elimination. Malar J 13:125

52. Bayoh MN, Mathias DK, Odiere MR, Mutuku FM, Kamau L, Gimnig JE et al (2010) Anopheles gambiae: historical population decline associated with regional distribution of insecticide-treated bed nets in western Nyanza Province, Kenya. Malar J 9:1-12

53. Bayoh M, Walker ED, Kosgei J, Ombok M, Olang GB, Githeko AK et al (2014) Persistently high estimates of late night, indoor exposure to malaria vectors despite high coverage of insecticide treated nets. Parasit Vectors 7:380

54. Hawley WA, Phillips-Howard PA, ter Kuile FO, Terlouw DJ, Vulule JM, Ombok M et al (2003) Community-wide effects of permethrin-treated bed nets on child mortality and malaria morbidity in western Kenya. Am J Trop Med Hyg 68(4 Suppl):121-127

55. WHO (1975) Manual on practical entomology in malaria. Part 1: vector bionomics and organization of anti-malaria activities. World Health Organization, Geneva

56. Service MW (1977) A critical review of procedures for sampling populations of adult mosquitoes. Bull Entomol Res 67:343-382

57. Kristan M, Abeku TA, Beard J, Okia M, Rapuoda B, Sang J et al (2008) Variations in entomological indices in relation to weather patterns and malaria incidence in East African highlands: implications for epidemic prevention and control. Malar J 7:231

58. White MT, Griffin JT, Churcher TS, Ferguson NM, Basáñez M-G, Ghani AC (2011) Modelling the impact of vector control interventions on Anopheles gambiae population dynamics. Parasit Vectors 4:153
59. Ministry of Health (2009) National malaria strategy 2009-2017. Division of Malaria Control, Ministry of Public Health and Sanitation, Nairobi

60. Banda JJ, Ngulube TJ, Basu S, Chimumbwa JM, Loolpapit M, Renshaw M (2004) Kenya roll back malaria consultative mission: essential actions to support the attainment of the Abuja targets. RBM Partnership, Geneva

61. Munyekenye OG, Githeko AK, Zhou G, Mushinzimana E, Minakawa N, Yan G (2005) Plasmodium falciparum spatial analysis, western Kenya highlands. Emerg Infect Dis 11:1571-1577

62. Division of Malaria Control, Ministry of Public Health and Sanitation (2010) 2010 Kenya malaria indicator survey. Division of Malaria Control, Ministry of Public Health and Sanitation, Nairobi

63. Ndenga B, Githeko A, Omukunda E, Munyekenye G, Atieli H, Wamai P et al (2006) Population dynamics of malaria vectors in western Kenya highlands. J Med Entomol 43:200-206

64. Chaves LF, Hashizume M, Satake A, Minakawa N (2012) Regime shifts and heterogeneous trends in malaria time series from western Kenya Highlands. Parasitology 139:14-25

65. Snow RW, Marsh K (2002) The consequences of reducing transmission of Plasmodium falciparum in Africa. Adv Parasitol 52:235-264

66. Hay SI, Guerra CA, Tatem AJ, Noor AM, Snow RW (2004) The global distribution and population at risk of malaria: past, present, and future. Lancet Infect Dis 4:327-336

67. Enayati A, Hemingway J (2010) Malaria management: past, present, and future. Annu Rev Entomol 55:569-591

68. Githeko AK, Ototo EN, Guiyun Y (2012) Progress towards understanding the ecology and epidemiology of malaria in the western Kenya highlands: opportunities and challenges for control under climate change risk. Acta Trop 121:19-25

69. Howard AF, Omlin FX (2008) Abandoning small-scale fish farming in western Kenya leads to higher malaria vector abundance. Acta Trop 105:67-73

70. Stuckey EM, Stevenson JC, Cooke MK, Owaga C, Marube E, Oando G et al (2012) Simulation of malaria epidemiology and control in the highlands of western Kenya. Malar J 11:357

71. USAID (2011) President's Malaria Initiative: Malaria Operational Plan

72. Mulambalah CS, Ngeiywa MM, Donald N, Vulule JM (2011) Diversity of Anopheles species and prevalence of malaria in a highland area of western Kenya. J Parasitol Vector Biol 3:33-39

73. Okara RM, Sinka ME, Minakawa N, Mbogo CM, Hay SI, Snow RW (2010) Distribution of the main malaria vectors in Kenya. Malar J 9:1-11

74. Ndenga BA, Simbauni JA, Mbugi JP, Githeko AK, Fillinger U (2011) Productivity of malaria vectors from different habitat types in the western Kenya highlands. PLoS One 6:e19473

75. Hayes RJ, Bennett S (1999) Simple sample size calculation for clusterrandomized trials. Int J Epidemiol 28:319-326

76. Miller TA, Stryker RG, Wilkinson RN, Esah S (1970) The influence of moonlight and other environmental factors on the abundance of certain mosquito species in light-trap collections in Thailand. J Med Entomol 7:555-561

77. Bowden J (1973) The influence of moonlight on catches of insects in light-traps in Africa. Part I. The moon and moonlight. Bull Entomol Res 63:113-128

78. Bidlingmayer WL (1967) A comparison of trapping methods for adult mosquitoes: species response and environmental influence. J Med Entomol 4:200-220

79. Moon phase calculator. http://www.timeanddate.com/calendar/moonphases.html

80. Southwood TRE, Henderson PA (2007) Ecological methods, 3rd edn. Blackwell Publishing, Oxford

81. Himeidan YE, Hamid EE, Thalib L, Elbashir MI, Adam I (2007) Climatic variables and transmission of falciparum malaria in New Halfa, eastern Sudan. East Mediterr Health J 13:17-24

82. Odetoyinbo JA (1969) Preliminary investigation on the use of a lighttrap for sampling malaria vectors in the Gambia. Bull World Health Organ 40:547-560

83. Battle K, Drakeley C (2009) Evaluation of mosquito biting behaviour in two villages in highland western Kenya. MSc. The London School of Hygiene and Tropical Medicine

84. Gillies MT, Coetzee M (1987) A supplement to the anophelinae of Africa South of the Sahara (Afrotropical Region), vol 15. South African Institute of Medical Research, Johannesburg 
85. Gillies MT, De Meillon B (1968) The anophelinae of Africa south of the Sahara (Ethiopian Zoogeographical Region). South African Institute of Medical Research, Johannesburg

86. Detinova TS, Gillies MT (1964) Observations on the determination of the age composition and epidemiological importance of populations of Anopheles gambiae Giles and Anopheles funestus Giles in Tanganyika. Bull World Health Organ 30:23-28

87. Scott JA, Brogdon WG, Collins FH (1993) Identification of single specimens of the Anopheles gambiae complex by the polymerase chain reaction. Am J Trop Med Hyg 49:520-529

88. Beier JC, Perkins PV, Wirtz RA, Whitmire RE, Mugambi M, Hockmeyer WT (1987) Field evaluation of an enzyme-linked immunosorbent assay (ELISA) for Plasmodium falciparum sporozoite detection in anopheline mosquitoes from Kenya. Am J Trop Med Hyg 36:459-468

89. Wirtz RA, Avery M, Benedict M (2007) Plasmodium sporozoite ELISA. In: Methods in Anopheles research. The Malaria Research and Reference Reagent Resource Center, pp 1-8

90. Systematic Catalog of Culicidae. http://www.mosquitocatalog.org

91. Huho B, Briët O, Seyoum A, Sikaala C, Bayoh N, Gimnig J et al (2013) Consistently high estimates for the proportion of human exposure to malaria vector populations occurring indoors in rural Africa. Int J Epidemiol 42:235-247

92. Atieli HE, Zhou G, Afrane Y, Lee MC, Mwanzo I, Githeko AK et al (2011) Insecticide-treated net (ITN) ownership, usage, and malaria transmission in the highlands of western Kenya. Parasit Vectors 4:113

93. McCann R, Ochomo E, Bayoh M, Vulule J, Hamel M, Gimnig J et al (2014) Reemergence of Anopheles funestus as a vector of Plasmodium falciparum in western Kenya after long-term implementation of insecticidetreated bed nets. Am J Trop Med Hyg 90:597-604

94. Coetzee M, Fontenille D (2004) Advances in the study of Anopheles funestus, a major vector of malaria in Africa. Insect Biochem Mol Biol 34:599-605

95. Lefèvre T, Gouagna L-C, Dabiré KR, Elguero E, Fontenille D, Renaud F et al (2009) Beyond nature and nurture: phenotypic plasticity in bloodfeeding behavior of Anopheles gambiae s.s. when humans are not readily accessible. Am J Trop Med Hyg 81:1023-1029

96. White GB (1972) The Anopheles gambiae complex and malaria transmission around Kisumu, Kenya. Trans R Soc Trop Med Hyg 66:572-581

97. Bousema T, Griffin JT, Sauerwein RW, Smith DL, Churcher TS, Takken W et al (2012) Hitting hotspots: spatial targeting of malaria for control and elimination. PLoS Med 9:e1001165

98. Kelly-Hope LA, McKenzie FE (2009) The multiplicity of malaria transmission: a review of entomological inoculation rate measurements and methods across sub-Saharan Africa. Malar J 8:1-19

99. Durnez L, Van Bortel W, Denis L, Roelants P, Veracx A, Trung HD et al (2011) False positive circumsporozoite protein ELISA: a challenge for the estimation of the entomological inoculation rate of malaria and for vector incrimination. Malar J 10:195

100. Biney EJ, Berkard H, Sakyi KY, Appawu M, Wilson MD, Boakye DA (2010) The impact of house screening on biting behavior of Anopheles species and transmission of lymphatic filariasis and malaria in Gomoa Mampong, a rural community in Ghana. Am J Trop Med Hyg 83(Suppl 1):Poster 1014
101. Lindsay SW, Jawara M, Paine K, Pinder M, Walraven GE, Emerson PM (2003) Changes in house design reduce exposure to malaria mosquitoes. Trop Med Int Heal 8:512-517

102. Silver JB (2008) Mosquito ecology. Field sampling methods, 3rd edn. Springer, New York, p 165

103. Mboera LE (2005) Sampling techniques for adult Afrotropical malaria vectors and their reliability in the estimation of entomological inoculation rate. Tanzania Health Res Bull 7:117-124

104. Mbogo CMN, Glass GE, Forster D, Kabiru EW, Githure Jl, Ouma JH et al (1993) Evaluation of light traps for sampling Anopheline mosquitoes in Kilifi, Kenya. JAMA 9:260-263

105. Davis JR, Hall T, Chee EM, Majala A, Minjas J, Shiff CJ (1995) Comparison of sampling anopheline mosquitoes by light-trap and human-bait collections indoors at Bagamoyo, Tanzania. Med Vet Entomol 9:249-255

106. Lines JD, Curtis CF, Wilkes TJ, Njunwa KJ (1991) Monitoring human-biting mosquitoes (Diptera: Culicidae) in Tanzania with light-traps hung beside mosquito nets. Bull Entomol Res 81:77-84

107. Mathenge EM, Omweri GO, Irungu LW, Ndegwa PN, Walczak E, Smith TA et al (2004) Comparative field evaluation of the Mbita trap, the Centers for Disease Control light trap, and the human landing catch for sampling of malaria vectors in western Kenya. Am J Trop Med Hyg 70:33-37

108. Le Goff G, Carnevale P, Robert V (1993) [Comparison of catches by landings on humans and by CDC light traps for sampling of mosquitoes and evaluation of malaria transmission in South Cameroon] (in French). Ann Soc Belg Med Trop 73:55-60

109. Fornadel CM, Norris LC, Norris DE (2010) Centers for Disease Control light traps for monitoring Anopheles arabiensis human biting rates in an area with low vector density and high insecticide-treated bed net use. Am J Trop Med Hyg 83:838-842

110. Overgaard HJ, Saebo S, Reddy MR, Reddy VP, Abaga S, Matias A et al (2012) Light traps fail to estimate reliable malaria mosquito biting rates on Bioko Island, Equatorial Guinea. Malar J 11:56

111. Githeko AK, Service MW, Mbogo CM, Atieli FA, Juma FO (1994) Sampling Anopheles arabiensis, A. gambiae sensu lato and A. funestus (Diptera: Culicidae) with CDC light-traps near a rice irrigation area and a sugarcane belt in western Kenya. Bull Entomol Res 84:319-324

112. Faye O, Diallo S, Gaye O, Ndir O (1992) [Comparison of the efficacy of CDC light traps and human bait for sampling Anopheles populations. Results obtained in the Bignona zone of Senegal] (in French). Bull Soc Pathol Exot 85:185-189

113. Ismail IAH, Pinichpongse S, Chitprarop U, Prasittisuk C, Schepens J (1982) Trials with CDC and Monks Wood light-traps for sampling malaria vectors in Thailand. World Health, WHO/VBC/82

114. Costantini C, Sagnon NF, Sanogo E, Merzagora L, Coluzzi M (1998) Relationship to human biting collections and influence of light and bednet in CDC light-trap catches of West African malaria vectors. Bull Entomol Res 88:503-511

\section{Submit your next manuscript to BioMed Central and take full advantage of:}

- Convenient online submission

- Thorough peer review

- No space constraints or color figure charges

- Immediate publication on acceptance

- Inclusion in PubMed, CAS, Scopus and Google Scholar

- Research which is freely available for redistribution

Submit your manuscript at

www.biomedcentral.com/submit
C Biomed Central 